\title{
APPrendendo - Um aplicativo de apoio aos processos de ensino e aprendizagem voltado aos Tablets Educacionais
}

\author{
Jorge Menezes Júnior ${ }^{1}$, Karla Marques da Rocha ${ }^{1}$, Gustavo Girardon dos Reis ${ }^{2}$, \\ Lucas Gaedicke ${ }^{2}$, Pedro Moura Garcia², Rodrigo Machado², Willian Gerstberger ${ }^{2}$ \\ ${ }^{1}$ Programa de Pós-Graduação em Tecnologias Educacionais em Rede - Universidade \\ Federal de Santa Maria (UFSM) \\ CEP - 97.105-900 - Santa Maria - RS - Brasil \\ ${ }^{2}$ Universidade Federal do Pampa (UNIPAMPA) - Curso de Engenharia de Software \\ CEP - 97.546-550 - Alegrete - RS - Brasil \\ \{jorgemenezesjr,karlamarquesdarocha, rodrigo.blizzard92, williansamuelg\} \\ @gmail.com, \{ggirardon,pedrogarcia\}@alunos.unipampa.edu.br, \\ lukas.gaedicke@hotmail.com
}

\begin{abstract}
Resumo. Este artigo apresenta o protótipo do aplicativo APPrendendo. Desenvolvido para os Tablets Educacionais, recebidos pelos professores da rede estadual de ensino, através da ação governamental, Educação Digital Politica para computadores interativos e tablets, tem por objetivo promover a utilização desses recursos pelos professores em suas práticas pedagógicas. A metodologia de desenvolvimento será a "Engenharia Web". No desenvolvimento, a abordagem hibrida. HTML5, CSS3, Java Script, Bootstrap, AJAX, PHP, Mysql, as ferramentas Intel XDK, Balsamic Mockup e Bitbucket constituem as tecnologias. Oficinas com a participação dos professores subsidiarão o desenvolvimento e contribuição do aplicativo.
\end{abstract}

\section{Cenário de uso}

A ação do governo brasileiro denominada Educação Digital - Política para computadores interativos e tablets investiu, a partir do ano de 2013, na cessão de Tablets Educacionais a todos os professores do ensino médio das escolas estaduais brasileiras com o objetivo de inserir a utilização dessa tecnologia em sala de aula. No entanto, através de uma pesquisa realizada no ano de 2015, nas escolas estaduais da cidade de Alegrete, no estado do Rio Grande do Sul, confirmou-se que tais recursos estavam sendo subutilizados, e que o projeto não atingira seu objetivo. Partindo deste cenário, a pesquisa relacionada ao Programa de Pós-Graduação em Tecnologias Educacionais em Rede da Universidade Federal de Santa Maria (UFSM) e ao projeto de extensão Tecnologias Educacionais - Estudo, desenvolvimento e aplicação de soluções inovadoras para a educação, realizado na Universidade Federal do Pampa (UNIPAMPA), da qual o protótipo apresentado faz parte, propôs o desenvolvimento de um aplicativo para os Tablets Educacionais considerando que um fator decisivo para a sua não utilização se deu pela carência de aplicativos funcionais específicos que atendessem às demandas dos professores. Formou-se então, um grupo constituído pelos pesquisadores, professores das escolas que aceitaram participar da pesquisa e alunos voluntários do curso de Engenharia de Software da Universidade Federal do Pampa, campus Alegrete-RS, para trabalhar no desenvolvimento de um aplicativo, em forma de Web Quis, o APPrendendo. O objetivo principal do APPrendendo é incentivar os 
professores a utilizarem seus Tablets Educacionais e tornarem o dispositivo mais presente em suas tarefas didáticas, retomando assim, um projeto governamental até então estagnado. A proposta de Web Quis baseia-se no conceito de desafio, em que o professor cria perguntas sobre determinado conteúdo do seu interesse, geralmente algo visto em sala de aula, e propõe aos seus alunos que resolvam tais desafios. Os alunos, por sua vez, de posse do aplicativo em seus smartphones, tablets ou microcomputadores, poderão resolvê-los ganhando pontos em função dos seus acertos, e evoluirão em um sistema de ranqueamento. No desenvolvimento do aplicativo APPrendendo, a equipe busca fazer com que a interação professor-aplicativo, incentive a utilização pelo professor, de todos os recursos disponíveis no dispositivo, como por exemplo: gravação de áudio, gravação de vídeo, câmeras, imagens e conteúdo de internet. Essa característica busca sensibilizar o professor em relação às possibilidades metodológicas que os recursos podem proporcionar para atividades de ensino-aprendizagem. Além do objetivo primário, que é promover a utilização do recurso Tablet Educacional, o aplicativo poderá abrir um novo canal de comunicação entre professor-aluno, bem como servir de reforço de conteúdos vistos em sala de aula em um ambiente externo à escola. Mesmo não havendo um caráter competitivo, o aplicativo também poderá servir para auto avaliação do aluno e seu aprendizado e do professor e de seu ensino.

\section{Desenvolvimento}

Dentre as três abordagens de desenvolvimento para aplicativos móveis existentes, que são: a nativa, que utiliza a linguagem de programação nativa do sistema operacional do dispositivo, a web, que se baseia somente em tecnologias web, funcionando no navegador dos sistemas operacionais dos dispositivos, e a híbrida, que utiliza as tecnologias web, no entanto também as tecnologias que dão acesso aos recursos do hardware do dispositivo, foi escolhida a última. A escolha levou em conta os requisitos do aplicativo, as características dos Tablets Educacionais e estudos como o de Andrade e Albuquerque (2015) e Litayem et al. (2015) que apresentaram um comparativo entre as vantagens e desvantagens de cada abordagem. O próximo passo foi a definição da metodologia e das tecnologias de desenvolvimento. Como metodologia, foi escolhida a Engenharia Web de Presmann e Lowe (2011). Através do paradigma evolutivo, baseado em protótipo, o projeto se dividiu em etapas: comunicação, planejamento, modelagem, construção e implantação. A fase da comunicação consiste de oficinas realizadas com a participação dos professores colaboradores da pesquisa e de alunos voluntários do curso de Engenharia de Software da Universidade Federal do Pampa (UNIPAMPA). Nessas oficinas, são apresentadas e validadas pelos professores as telas e funcionalidades do protótipo, e são gerados a partir dessas telas os requisitos que deverão ser apresentados na oficina subsequente já em sua versão de produção, ou seja, sendo executada no Tablet Educacional de cada professor. Os professores levam seus Tablets Educacionais nas oficinas e já testam e validam as implementações feitas com base nas informações levantadas no encontro anterior. No projeto, são previstas quatro oficinas até a entrega da versão final do aplicativo. O protótipo apresentado representa o resultado de três desses encontros. As telas de protótipo são criadas a partir da ferramenta Balsamic Mockup. Como ambiente de desenvolvimento, foi utilizado o Intel XDK, que consiste numa plataforma cruzada de desenvolvimento com suporte a HTML5, CSS3, Java Script, Bootstrap, AJAX e PHP, além da biblioteca Apache Cordova. O Intel XDK é que 
permite o desenvolvimento híbrido, pois apesar de utilizar tecnologias web, ele permite a criação de um pacote APK para o sistema operacional que roda nos Tablets Educacionais, o Android. Outra ferramenta utilizada é o Bitbucket, que consiste num ambiente de controle de versões que permite o desenvolvimento de ferramentas em equipe por diversos programadores de forma paralela.

\section{Apresentação do Software}

O APPrendendo é um aplicativo/jogo baseado em desafios. Inspirado no conceito de Web Quis, ele permite ao professor de qualquer escola, disciplina e/ou curso, criar e distribuir conteúdo para seus alunos em forma de um jogo de perguntas e respostas. $\mathrm{O}$ professor de posse, preferencialmente, de seu Tablet Educacional, poderá criar desafios utilizando para isso todos os recursos multimídias disponíveis nessa tecnologia como por exemplo: vídeos da Internet, imagens obtidas pela câmera do Tablet, da Internet, vídeos de sites como Youtube, vídeos gravados pelo próprio professor com auxílio da câmera do Tablet, além de conteúdos criados utilizando apenas o teclado virtual do Tablet. Todas essas funcionalidades estão incorporadas no aplicativo APPrendendo. Uma vez criado o desafio, o professor poderá convidar seus alunos a participarem através da vinculação de uma turma pré-cadastrada. Caberá aos alunos, de posse também de um dispositivo móvel, ou de um microcomputador, responder as questões colocadas e tentar o maior número de acertos. Assim, ganharão pontos que ao fim lhes colocarão em um sistema de ranqueamento, não competitivo, apenas para incentivo, ou autoconhecimento sobre sua aprendizagem a respeito do assunto abordado. Sendo o objetivo principal do aplicativo, o incentivo à utilização do professor do Tablet Educacional, pode se dizer que dentre os objetivos secundários estão a promoção de um novo meio de interação aluno-professor, a possibilidade de utilizar os desafios como forma de reforço de conteúdos vistos em sala de aula, além de servir tanto para o professor quanto para o aluno como forma de avaliação do que está sendo ensinado e do que está sendo aprendido. Na sequência, as principais telas do protótipo já validadas até o momento: 
V Congresso Brasileiro de Informática na Educação (CBIE 2016)

Anais dos Workshops do V Congresso Brasileiro de Informática na Educação (CBIE 2016)

Telas de primeiro acesso ao sistema e cadastro. Percebe-se que o aplicativo é o mesmo tanto para professor quanto para aluno, diferenciado os usuários pelo perfil.
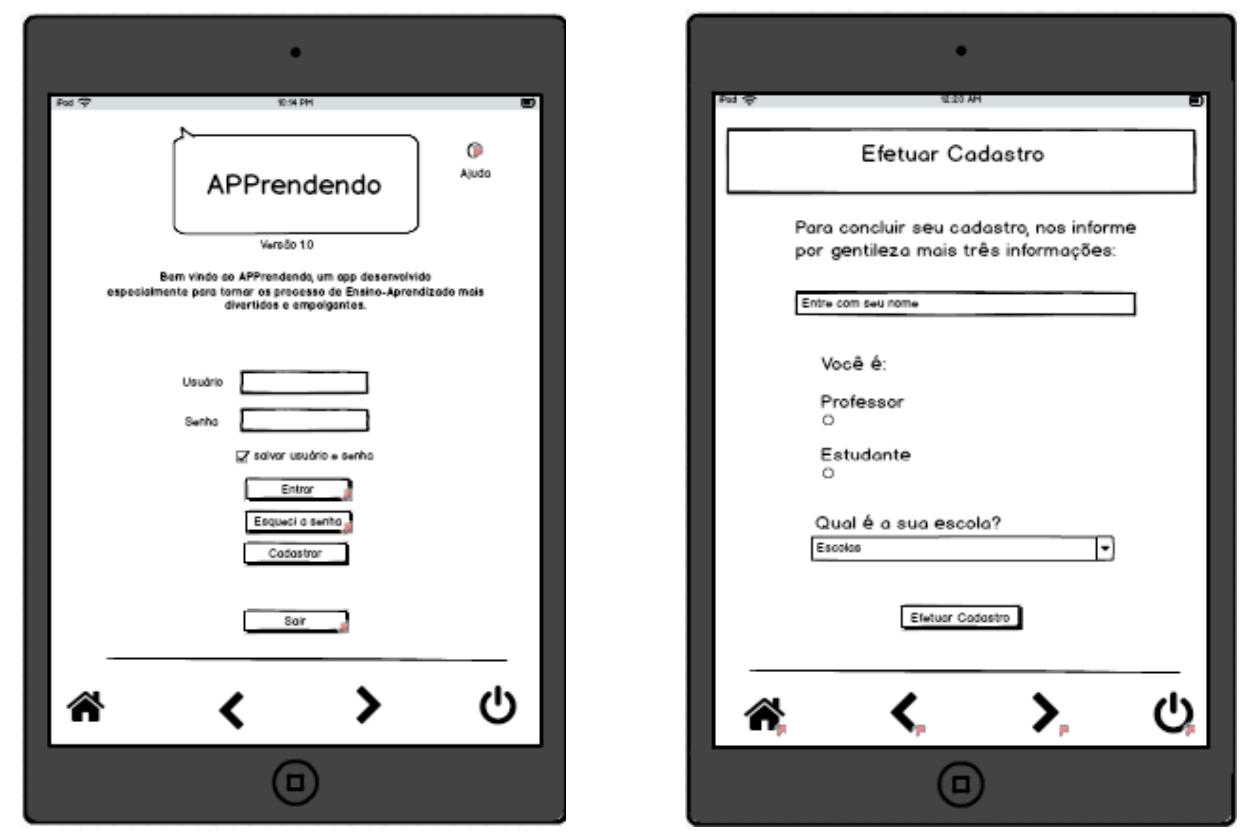

Tela inicial do aplicativo, para professores à esquerda e alunos à direita. Baseada no conceito de Springboard segundo Neil (2012). Todas as funcionalidades estão presentes à disposição do usuário.
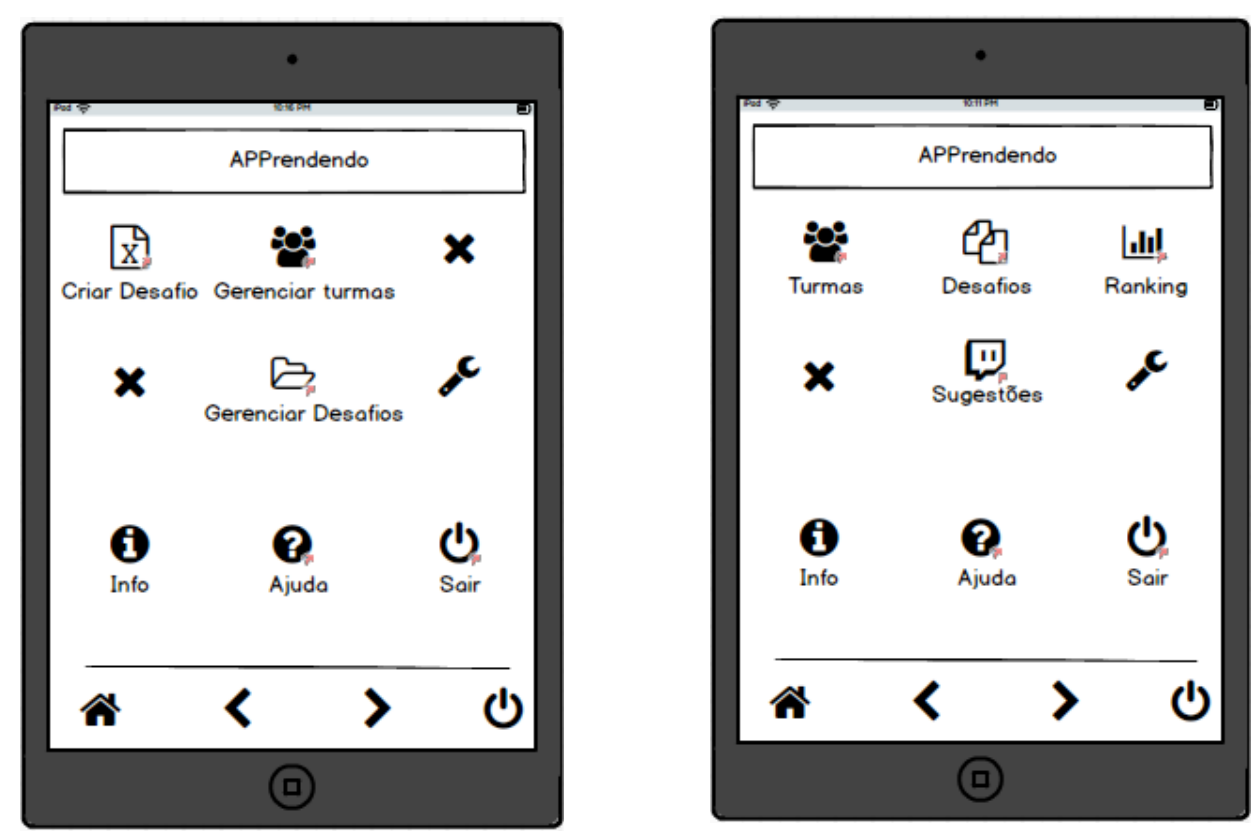

Telas principais do sistema. Apresentam a criação do desafio, associando-o a uma turma e adicionando as questões que farão parte dele. Um nome deve ser especificado bem como a área e a disciplina a que aquele desafio estará vinculado. A segunda tela representa a adição de questões. Nota-se que o enunciado da questão propõe a utilização dos recursos multimídias oferecidos pelo Tablet Educacional, como câmera, áudio e 
V Congresso Brasileiro de Informática na Educação (CBIE 2016)

Anais dos Workshops do V Congresso Brasileiro de Informática na Educação (CBIE 2016)

imagens. O professor informa o enunciado e define as questões, sendo que a primeira deve ser a correta. Caberá ao aplicativo randomicamente embaralhar as alternativas.
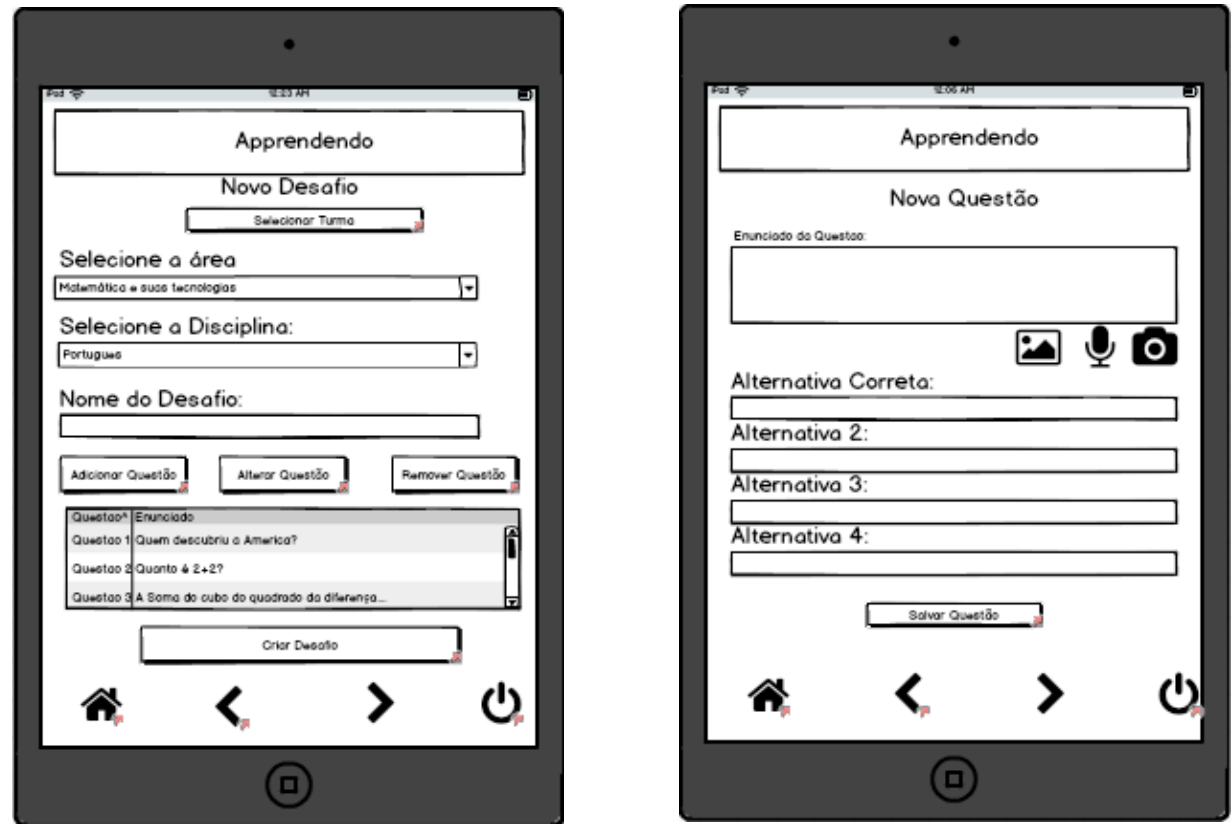

Tela de criação das turmas. O professor será livre para criar as turmas de acordo com a sua necessidade. Não necessariamente, ele deverá seguir a estrutura da sua escola. Essa funcionalidade foi pensada para permitir a autonomia do professor em relação à sua escola para a criação de turmas. O código de acesso representa a "chave" que cada aluno convidado a participar da turma receberá. Essa funcionalidade restringirá o acesso não autorizado de alunos em turmas das quais não fazem parte.

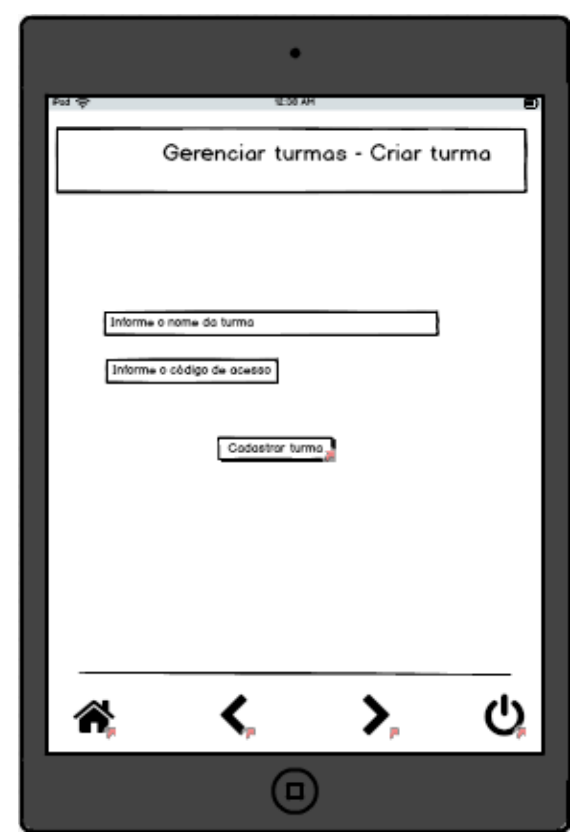


V Congresso Brasileiro de Informática na Educação (CBIE 2016)

Anais dos Workshops do V Congresso Brasileiro de Informática na Educação (CBIE 2016)

Telas da interação dos alunos na seleção do desafio e na resolução do mesmo.
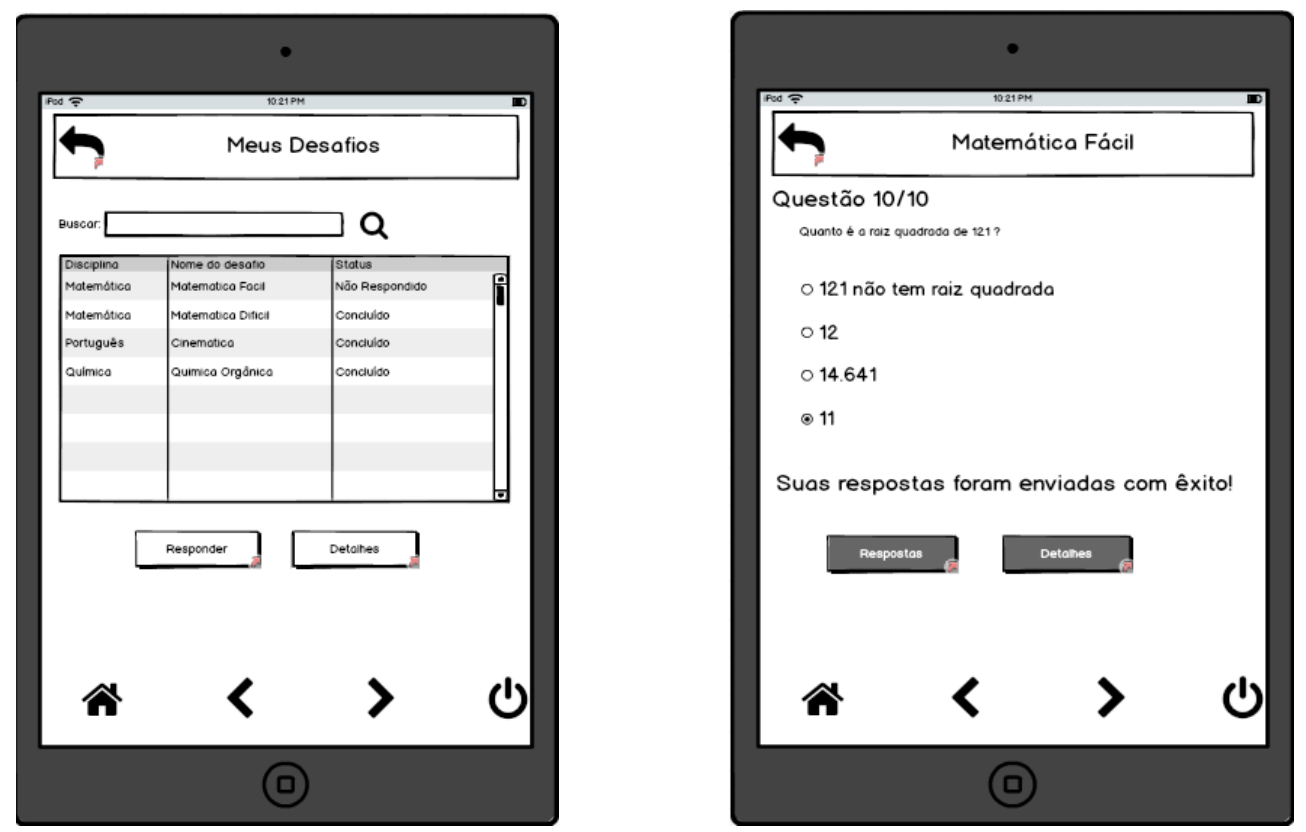

Por fim, as telas em que o aluno poderá verificar seu desempenho no desafio e após, o seu posicionamento no ranking conforme os seus acertos.
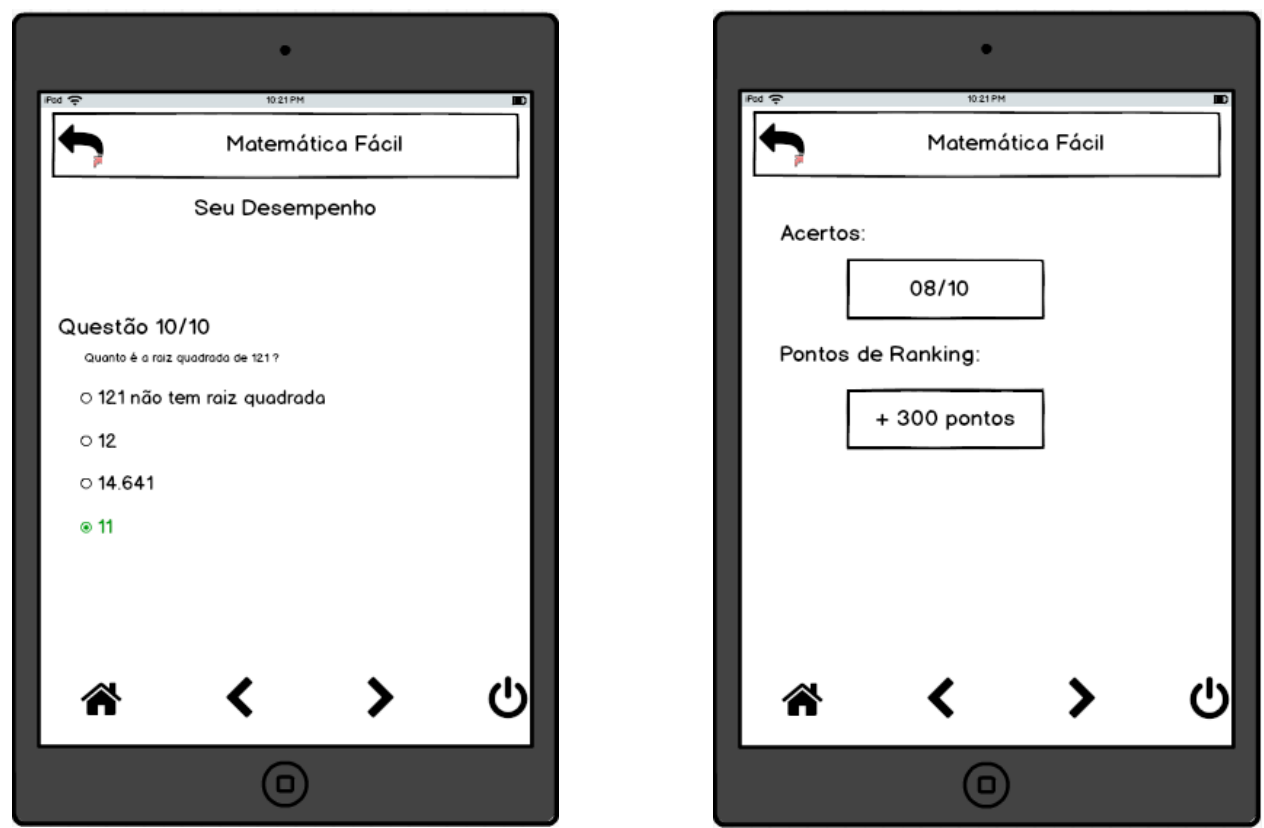
V Congresso Brasileiro de Informática na Educação (CBIE 2016)

Anais dos Workshops do V Congresso Brasileiro de Informática na Educação (CBIE 2016)

Sistema de ranqueamento das turmas e do aluno:
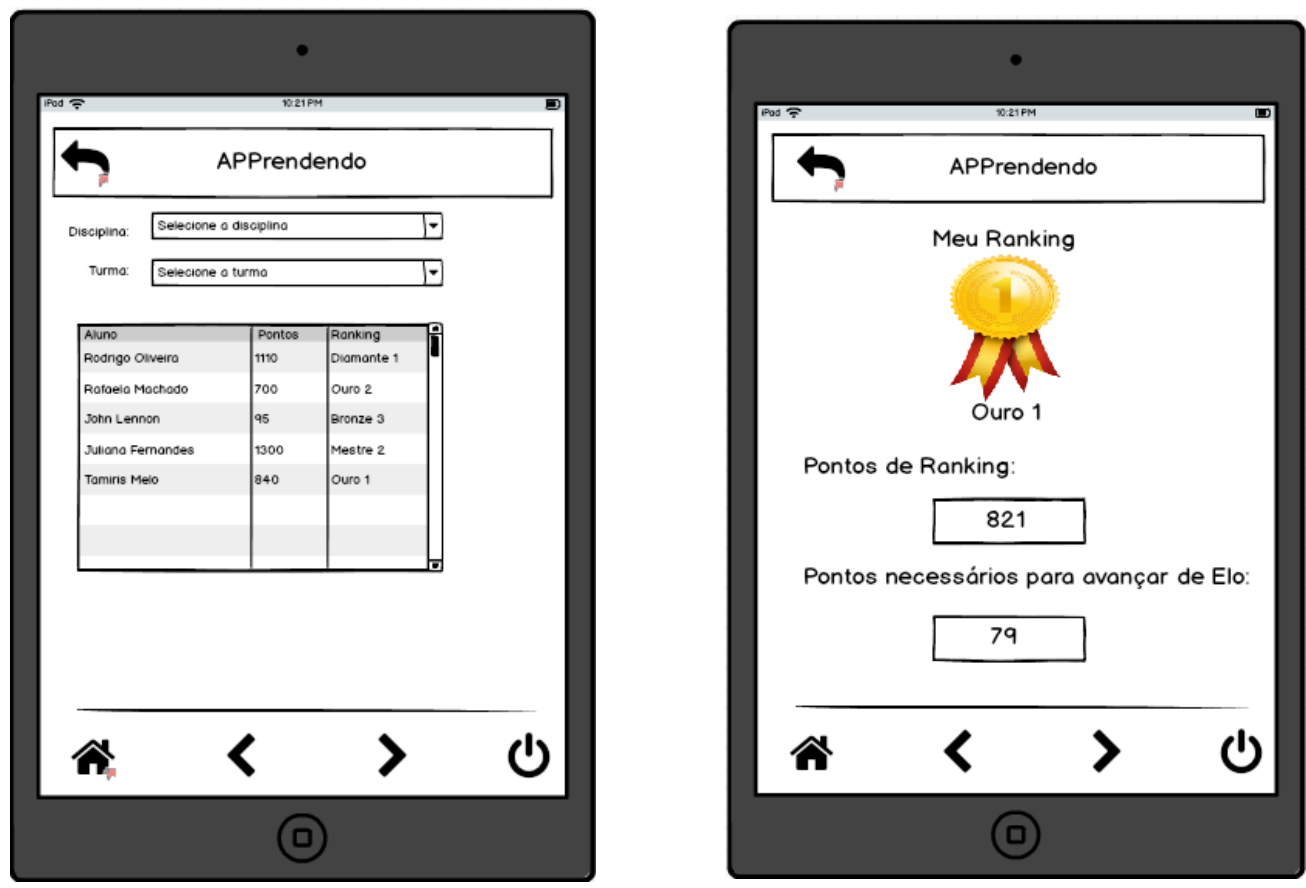
Para realizar o download da versão do protótipo do aplicativo, acesse o endereço www.apprendendo.esy.es. Neste local, consta também o vídeo demonstrativo da ferramenta.

\section{Considerações finais}

O protótipo de aplicativo apresentado buscará, quando colocado em produção, promover a reinserção de uma tecnologia, o Tablet Educacional, que as escolas receberam através de uma política governamental de incentivo às TIC na educação, na categoria de potencial ferramenta didático-pedagógica. $O$ grande diferencial para atingir esse objetivo foi a chamada para a participação na criação do aplicativo dos principais interessados no projeto, os professores, que além do conhecimento da realidade, dos conflitos, das dificuldades e das potencialidades encontradas nas escolas públicas do nosso país, sabem os reais anseios com relação às tecnologias da informação e comunicação e como elas podem contribuir para a melhoria da educação. Outro diferencial do presente projeto é a participação de graduandos do curso de Engenharia de Software, que articulados através de um projeto de extensão universitária, contribuem com seus conhecimentos na qualificação do projeto de desenvolvimento, permitindo assim, a entrega de um produto que atenda aos requisitos mínimos de qualidade acordados. Por hora, os resultados obtidos através das oficinas realizadas representam três quartos do aplicativo, e consistem na interação professor-aplicativo. Como tarefa restante para a conclusão do projeto, será necessária a implementação da parte aluno-aplicativo e a verificação se de fato o aplicativo será capaz de fomentar a utilização do Tablet Educacional pelo professorado. Uma vez o produto entregue aos professores, a próxima meta é a ampliação do escopo de utilização da ferramenta. Divulgar em nível nacional e internacionalizar o APPrendendo, oferecendo-o em outros idiomas, será o grande desafio proposto. Pela sua característica específica, baseada em desafios, mas também genérica, por permitir ao professor autonomia na criação de desafios e turmas e na forma de submetê-los a um grupo de alunos, o aplicativo poderá ser utilizado em qualquer tipo de escola, curso e turma, por qualquer educador em qualquer nível e contexto educacional.

\section{References}

Andrade, P. R. M. and Albuquerque, A. B. (2015). Cross Plataform - A Comparative Study. In: Internacional Journal of Computer Science \& Information Technology, India.

Litayem, N., Dhupia, B. and Rubab, S. (2015). Review of Cross-Plataforms for Mobile Learning Application Development. In Internacional Journal of Advanced Computer Science and Aplications, England.

Pressman, R. and Lowe, D. (2009). Engenharia Web, LTC , $1^{\text {st }}$ edition.

Neil, T. (2012). Padrões de Design para Aplicativos Móveis, O’Reilly Novatec, $1^{\text {st }}$ edition. 